https://helda.helsinki.fi

\title{
3D Computer-Aided Design and Manufacturing in Oromaxillofacial Surgery
}

\section{Kontio, Risto}

Springer Nature Switzerland

2019-12-03

Kontio , R \& Seppänen-Kaijansinkko , R 2019 , 3D Computer-Aided Design and Manufacturing in Oromaxillofacial Surgery . in R Seppänen-Kaijansinkko (ed.), Tissue Engineering in Oral and Maxillofacial Surgery . 1. ed. edn , Springer Nature Switzerland , Cham , pp. 123-140 . https://doi.org/10.1007/978-3-030-24517-7

http://hdl.handle.net/10138/337058

https://doi.org/10.1007/978-3-030-24517-7

unspecified

acceptedVersion

Downloaded from Helda, University of Helsinki institutional repository.

This is an electronic reprint of the original article.

This reprint may differ from the original in pagination and typographic detail.

Please cite the original version. 
Chapter 9

\title{
3-D Computer Aided Design and Manufacturing
}

\author{
Risto Kontio \\ ORCID ID 0000-0003-4734-1593 \\ Riitta Seppänen-Kaijansinkko \\ ORCID ID 0000-0001-5348-7121
}

Department of Oral and Maxillofacial Diseases, Clinicum, University of Helsinki, Finland and Department of Oral and Maxillofacial Surgery, Helsinki University Hospital, Finland

Keywords: Surgical planning,

3-D design and solid scaffold production,

Bioprinting 


\section{Abstract}

As imaging possibilities of tumor patients have improved, instead of secondary reconstruction, immediate reconstruction has gradually become state-of-the-art in oromaxillofacial surgery.

By using digital 3-D technology, surgeon can produce solid patient specific implants or scaffolds (PSI). Computer aided design and manufacturing can be carried out in few days. 3-D CAD - CAM technology offer multiple tools for reconstructive procedures: simulation, planning, training and production of patient specific scaffolds, on-lay implants as well as fixation plates. This technique is beneficial in patient education, as well.

Materials that can be used in 3D CAD-CAM are different for example titanium and different biomaterials. It can also be carried out with cells. This is called bioprinting.

In this chapter we will elaborate the background of 3D CAD-CAM, its use in experimental and clinical work, not forgetting the future insights. 


\subsection{Introduction}

The restoration of oromaxillofacial (OMF) bone, its form and function and rehabilitation of patients have always been a challenge. Available evidence of timing for restoration is vague, too.

The argument for the secondary reconstruction is that the possible recurrence will be easier to detect if the area has not been reconstructed immediately. With the development of better diagnostic techniques like magnetic resonance imaging (MRI), the early detection of tumor growth is not a significant problem today (1). In trauma surgery, immediate reconstruction of large defects has become gold standard. Without primary reconstruction, loss of continuity of bone leads to severe deformity and considerable difficulties with regard to speech, mastication, swallowing, and oral continence, as well as severe psychosocial problems $(2,3)$. Primary reconstruction prevents soft tissue retraction and fibrosis and minimizes the number of surgical procedures (4).

The reconstructive surgery should provide form and symmetry and enable function. The OMF region has a complex structure and reconstruction should restore volume, bone continuity and symmetry of the face. On the other hand, OMF soft and hard tissues support functions like mimics, mastication, swallowing, and articulation. The combination of both should be appreciated, and reconstruction should be considered as marriage of both aesthetic and functional objectives.

The aim of medical 3-D computer aided design and manufacturing (CAD - CAM) is to gain exact virtual 3-D digital copy of certain anatomic region in order to examine lesions, injuries or deformities, assess surgical preferences and to determine detailed plan of the upcoming surgical procedure outside of the patient by using digital 3-D technology. By using digital 3-D technology, surgeon can produce solid patient specific implants or scaffolds (PSI). 3-D digital technology helps surgical assessment, simulation and planning, giving the surgeon information enough to restore original anatomy, the form and function of OMF region, in both soft and hard tissue. The additional benefits are shortened operation time, improved recovery and decreased 
morbidity rate. All above mentioned are to improve the patient's quality of life. The main handicap is the prolonged time required for medical 3-D CAD - CAM that may delay the surgery.

During the last decade 3-D technology as well as tissue engineering (TE) has taken significant steps forwards. Several bone substitute materials and membranes have become available for reconstructive surgery. Translational research has brought new knowledge on stem cells and growth factors and has enabled their use in clinical reconstructive surgery $(5,6,7)$.

Based on improvements in 3-D CAD - CAM, digital models seem to be accurate enough for surgical planning and implant design procedures. Additive manufacturing and 3-D printing technology have improved during the last years and several biocompatible materials are available to be utilized in 3-D printing, as well. A few of these are also available for surgery, including titanium, polylactic acid (PLA) and hydroxyapatite.

Using additive manufacturing technology, complex structures and models difficult to manufacture by other means can be produced with ease. Timewise, patient-specific implants (plates, scaffolds and matrices) can be designed and produced in a few days with sufficient accuracy. 3-D CAD - CAM technology offer multiple tools for reconstructive procedures: simulation, planning, training and production of patient specific scaffolds, on-lay implants as well as fixation plates.

Growing number of translational and clinical research is available related to stem cells and bone reconstruction in OMF region $(8,9,10,11)$. During the last years, 3-D CAD - CAM has been introduced into field of tissue engineering (TE) $(12,13,14,15)$. Combined technique of 3-D CAD - CAM and TE will enable complex anatomical reconstructions with vital tissue $(5,6,7,12,16,17)$. TE providing proliferating cells and 3-D CAD - CAM technology enable anatomically precise scaffold and matrix manufacturing, both micro- and macro-anatomy, to support migration and proliferation of cells, regeneration and maturation of tissue, finally resulting in accurate autologous defect repair (13). 
Clinical reports of successfully performed reconstructions using 3-D CAD - CAM technique in OMF region are available, but only a few have used the combination of 3-D and TE techniques (18).

In spite of clear development of both 3-D technology and TE, facial reconstructive surgery will not be possible without high quality and multidisciplinary collaboration with microvascular surgeons, prosthodontists, periodontologists, speech therapists and many others.

\subsubsection{Medical 3-D}

The symmetry of OMF area and surgical site is mostly guided by fixation plates, scaffolds or onlay implants. Deformed or missing anatomical region reconstruction is guided by manually shaped or bent implants or fixation plates in order to gain suitable anatomical and functional outcome $(19,20,21)$. This procedure is performed during the surgery and is based on the surgeon's estimation and experience. Preformed plates and implants are now available and have gained popularity as can be expected. The shape of these implants has been obtained using the summary data of multiple anatomical models. Preformed plates are often accurate enough to reach sufficient anatomical shape and symmetry (22).

The use of 3-D CAD - CAM technique in medicine is still limited, although these techniques are widely used in the fields of architecture and engineering. Often only preoperative planning is carried out based on 3-D technique $(23,24)$.

Surgeons mostly deal with 2-D plane X-ray images or 2-D images obtained from computed tomography (CT) or magnetic resonance (MR) scans to gain insight into pathologies. This requires excellent visualization and orientation skills from the surgeon. The recent progress of 3-D renderings of CT, MR and echo imagery has improved visualization of complex pathologies.

3-D CAD - CAM technique has made it possible to execute virtual surgery together with implant designing. This enables digital simulation, precise planning of surgery and designing of complex virtual models that are printable $(25,26)$. Manufactured patient specific 3-D printed replicas can be used to study complex pathologies, simulate procedures, to teach students and advice patients (27). 
The aim of present 3-D CAD - CAM is to enable virtual visualization and virtual processing of person's anatomy in order to support surgical assessment and implant design $(6,28,29)$. This in turn will shorten operation time, speed the recovery of the patient and improve the overall outcome (Fig $1 \mathrm{a}, \mathrm{b}, \mathrm{c})$.

Medical 3-D CAD - CAM is considered as a process with five consecutive stages; 3-D imaging data, data conversion, digital planning, manufacturing of implant, and actual surgery (Fig 2).

The process has proven to be complicated including several stages $(6,28,29)$. Correct 3-D imaging has an extreme importance. The factors, such as tilt, slice thickness and distorsion should be adjusted properly in order to avoid erroneous database (Fig 3). CT algorithms have a great influence on data. Human eye recognizes less than thirty grey shades, while CT may produce up to 1000 shades. The CT algorithms accentuate the grey shades in question to result in best possible visualization and resolution of tissue. This means that grey shades are distorted and 3-D data achieved for processing is not comparable to original anatomy. Data formats of 3-D imaging and CAD - CAM are not compatible with each other and conversions between surface geometry and volumetric formats are mandatory. Before the 3-D data is available for CAD procedures, it needs to be processed. This process is semiautomatic or even automatic in some cases. The process is called segmentation. The anatomical region is made 'visible' for CAD software. Although segmentation has developed considerably, it includes risks for errors (31). After the process, the 3-D imaging data is available for surgeon to plan, simulate, and design patient specific implants. Virtual anatomical 3-D models and PSIs can be manufactured to solid replicas using 3-D printers or laser technique (Fig $4 \mathrm{a}, \mathrm{b}, \mathrm{c}$ ). It is notable that segmentation is not required in conventional engineering or architecture CAD.

PSIs are regarded as medical devices. This fact is notable when considering materials and printing processes for implantable objects. In Europe, the medical devices implanted to humans need to meet several specifications and directives such as Directive 93/42/EEC/ Article 1, Directive 2007/47/EU, and ASTM F136 -standard among others.

\subsubsection{Direct and indirect 3-D techniques}


Medical 3-D CAD and implant manufacturing can be performed either using direct or indirect technique. Both direct and indirect techniques require patient DICOM (Digital Imaging and Communications in Medicine) data received by 3-D imaging. Data is converted to 3-D standard tessellation language (STL) mesh format.

Direct technique refers to process where planning, designing and manufacturing is executed fully digitally without a manual intervention. After format conversion, the data based on imaging is uploaded into CAD - CAM software (Fig 5 a, b, c, d). Manipulation, planning of surgery and designing of the virtual PSIs including the virtual jigs is fully a digital process (Fig $6 \mathrm{a}, \mathrm{b}, \mathrm{c}, \mathrm{d}, \mathrm{e}$ ). Solid models or replicas can be printed based on these virtual objects by 3-D printing or by laser techniques $(32,33)$. Technology allows complex 3-D structures to be printed in a fully automated manner. Various printing techniques with numerous types of materials (commonly titanium) are used for these applications (33).

Indirect technique refers to process where image based 3-D data is simple converted to STL -format and manufactured into solid model, in other words virtual 3-D imaging data is copied as exact 3-D solid replica. These patient-specific solid anatomical replicas are used for planning of surgery. Shaping and bending of the implants and plates are performed manually accordingly (33).

\subsubsection{Anatomical replicas (models)}

Surgeons use patient specific anatomical solid replicas for assessing the extent of tumors or the degree of deformity in direct vision. The 3-D printed anatomical model seems to give a good representation of the actual pathology showing good accuracy, but is highly dependent on printing technique and equipment $(34,35,36)$.

Replicas are widely used in planning and simulation of surgery in maxillofacial surgery, dental surgery and neurosurgery $(37,38,39)$. Furthermore, implants and fixation plates are manually shaped (according to 3-D solid anatomical replicas) prior to surgery to match with defect or fracture. This results in an improved fit of the implant during the real time surgery. 3-D solid replicas allow manual preparing of drilling or 
cutting guides. Maxillofacial 3-D solid models are frequently used to enhance operational process. There is evidence that use of anatomical models shortens operation time $(35,39)$.

Patients can benefit from 3-D solid models as anatomical models improve patient's understanding of the specific pathology and the procedure chosen. This results in improved communication and greater patient satisfaction. Anatomical models can also assist medical and surgical students to improve their understanding and knowledge over deformities, pathologies and diseases.

\subsubsection{3-D guides}

There are only a few options to bridge virtual planning with real time surgery, to carry out operation accordingly. One is to use navigation to bridge virtual with real. Second option is to use 'jigs' or guides to execute the surgery according to the virtual plan. In fact, most of published studies are related to 3-D printing and surgical guides. They are used in orthopedics, neurosurgery, dental surgery, and maxillofacial surgery (39, 40,41 ). These guides are to transfer the virtual plan to actual surgery (Fig 7 a, b, c, d). Ciocca with coworkers defined this method as a three-step procedure that includes 1) virtual surgical planning (VSP), 2) design of customized surgical devices and 3) manufacturing these devices (30). The process starts from a CT scan data, which is converted to DICOM to allow manipulation by CAD software. After digital planning and designing, the solid guides are manufactured by 3-D printing. The authors used the guiding technique to reconstruct a secondary mandibular defect with a fibular free flap. The defect reconstruction was planned virtually together with surgical guides to correct the 3-D relationship of segments. Finally, the bone fixation plates were design to fixate and guide the fibula flap into the correct anatomical location. The guides and plates were manufactured using the direct metal laser sintering technique. Postoperative radiologic examination confirmed the correct position of the mandibular condyles and fibula flap. The authors conclude that virtual planning to produce patient-specific guides and plates restores function and accurate mandibular contour (28).

There is evidence that preoperative, digitally designed surgical planning gives a more accurate result compared with free hand reconstruction (29). However, the accuracy 
of guides can vary depending on multiple factors. Issues that may interfere with the accuracy are variations in 3-D printed elements, MRI or CT data and the time between the scan used for the production of the guide and the moment of surgery.

CAD - CAM technique can be used also for donor-site surgical planning. Foley and coworkers used the technique to shape the fibula and iliac crest flaps to create an orthognathically satisfactory anatomical contour (42). Eight consecutive patients underwent mandibular reconstruction using VSP. Guiding devices were designed and manufactured to transfer the virtual planning to both mandible and donor site. They concluded that the use of VSP and CAD - CAM technology for guides and the prebent reconstruction plates in executing the surgical procedure, resulted in an accurate surgical result. Surgical guides seem to reduce the operation time and improve surgical outcome. The authors conclude though, that the bias of this study is the small number of patients (42)

Shortened operation time has always been one of the major arguments for medical 3$D$ printing. The method provides the surgeon with pre-assessed and simulated surgery plan that may enable time reduction. Due to shorter theatre time, it may lead to fewer infection episodes and cost reduction. Although several papers conclude that the intraoperative use of 3-D guides decreases operation time, there are studies that do not support this finding $(28,39,40)$.

\subsection{Tissue engineering}

The material of choice for reconstructive bone surgery is autologous bone, either free graft or free vascularized flap. Bone grafts, including bone marrow have been in clinical use for years. Autologous bone defines criteria for ideal implant; histocompatible, nonimmunogenic, osteogenetic, osteoinductive, and osteoconductive. However, there are several drawbacks of autologous bone, both at the donor and at the recipient site. It would therefore be ideal to tissue engineer new bone either at the site, at the distant site or completely outside of patient and transfer it into defect area to execute accurate reconstruction. 
Tissue engineering (TE) and bone regeneration process requires several components that support the growth and maturation of the bone. Certain characteristics are considered to have prominent role in this process. 1) Osteoconductive matrix is essential to support the ingrowth of cells and to enhance new bone growth. 2) Osteoinductive proteins are required to start and maintain the mitogenesis of undifferentiated cells. 3) Osteogenic cells are necessary to generate new bone. In the bioreactor or human tissue-environment the above-mentioned components refer to biomaterials, cytokines, morphogenetic proteins, growth factors, stem cells, and to osteoblast precursors.

The matrix provides tissue specific environment, architecture and scaffold to enable bone formation. It should be osteoinductive/ -conductive, should give mechanical support, facilitate cell attachment and support cellular communication by allowing diffusion of nutrients, and by allowing signalling of cytokines and growth factors. There are several bone substitute materials, both alloplastic and allografts, that are candidates for ideal matrix. The most studied and clinically relevant materials are betatricalcium phosphate ( $\beta$-TCP) and biphasic calcium phosphate $(B C P)(14,15,18,43$, $44,45)$. There are also several reports on ceramics and bioactive glasses for bone substitutes $(46,47)$. Several allografts have ability to support bone growth and regeneration. Most used are anorganic bovine-derived hydroxyapatites and demineralized cancellous bone allografts. It remains to be seen if 3-D CAD - CAM technique enables design and manufacturing of these materials in a way that it facilitates bone growth.

Chapter 3 describes the use of cells in TE and Chapter 5 the use of growth factors in detail.

\subsection{3-D bioprinting}

The ability to print biological 'inks' opposite to traditional 3-D plastic and metal printing has resulted in the birth of the new bioprinting and TE research field. 3-D bioprinting is a computer-aided deposition of cells, biomaterials and biomolecules (48). The advantage of 3-D bioprinting compared to traditional tissue engineering is assembling cells, biomaterials and biomolecules in a spatially controlled manner to reproduce native tissue (49). In the future, due to high resolution characteristic of printing 
technology with novel printable biocompatible materials or 'inks', autologous tissue will be 3-D printed with macro-, and micro-architecture for reconstruction (Fig 8). The focus is by controlling the micro- and macrostructures to replicate complex native-like tissue architecture more reliably than by conventional methods. The wide synergy of research on biomaterials, and on 3-D bioprinting may enable restoring the form and functional reconstruction of OMF anatomy in the near future (50). 3-D bioprinting avoids donor site complications and immunosuppression. The main obstacles for wider use for 3-D bioprinting are related to biology, technology and regulatory issues.

Traditional 3-D printing is relatively simple and can be performed by the home computer using the proper software. For medical use, 3-D digital data is acquired from computed tomography, magnetic resonance imaging or laser scanning. This data can be manipulated by CAD - CAM software and be converted into STL format for printing (see paragraphs 'Medical 3-D modelling' and 'Direct and indirect 3-D techniques').

Fabrication of solid biomodel is carried out under the computer guidance to accurately and controlled manner deposit biological materials in a layer-by-layer fashion. 3-D bioprinter uses a nozzle to deposit biomaterials and cells according to xyz -axis to create the structure required. Fabricated solid model is then cultured in a bioreactor under specific conditions to produce specific and designed tissue engineered vital tissue.

\subsubsection{3-D Bioprinting techniques}

Currently, there are five main 3-D bioprinting techniques available (Table 1).

Stereolithography is regarded as the first 3-D printing technique (51). It uses a laser beam to polymerize photocurable resin layer-by-layer. It was initially developed to create high-resolution rapid prototypes, and therefore, due to lack of biocompatible resins has limited utility in biofabrication (52). However, improvements in biocompatibility and biodegradation of resins make stereolithography a promising bioprinting technology of the future $(53,54)$.

Extrusion-based bioprinting is based on the dispense of viscous bioink with biomaterials, biomolecules and cells through a nozzle $(55,56)$. After printing, the loose model can be solidified layer by layer. Cell viability in the printed 'tissue' seems to be 
as high as $90 \%$ in spite of forces and higher temperatures (57).

Laser-assisted bioprinting uses laser beam guided direct writing to induce the transfer of material from a source film onto a nearby receptor substrate in the form of a microdroplet (58). Apart from the doubts of minor cell viability compared to other 3-D techniques, laser-assisted bioprinting has been shown to print mammalian cells without affecting their function $(59,60)$.

Inkjet printing uses microdroplets of cells for printing of 3-D high-resolution models (61). Some of the major drawbacks includes cell viability at higher temperatures and pressures during the printing process that may lead to low cell density within the 3-D biomodel $(62,63)$. The advantages of this technique include the ability to combine multiple cell types and high resolution to print complex structures. Present research on this bioprinting suggests it as a promising technology (64).

The nanobioprinting uses nanoscale surface scaffolds to either increase cell-to-matrix interactions or incorporate nanoparticles into bioinks to non-invasively manipulate and track cells within tissue-engineered structures, e.g. adding magnetic iron oxide to 'bioink' and using magnet as an external manipulation $(65,66)$.

At present, the main challenges of $3-D$ bioprinting technologies are related to 1 ) biological, 2) technological and 3) regulatory aspects.

From biological perspectives, not only depositing cells, scaffolds and biomolecules in a spatially controlled manner is sufficient to create durable native-like tissue. A critical step is the transition of mechanically weak 3-D bioprinted neo-tissue constructs to native-like functional tissue that is transplantable into human. This development leading to functional tissue takes place in vitro bioreactor-based culture by using a various physiological conditions and growth factors and their combinations (67). It may also take place in vivo through the implantation of the 3-D bioprinted construct. Challenge is also a lack of vasculature and nutrition due to the size of TE constructs. Printing complex composite tissue has additional challenges, such as long biomanufacture times which may result in reduction of cell viability, and reduction in cellular dedifferentiation with loss of regenerative potential $(68,69)$.

From technological perspectives two obstacles are still unsolved. The microstructure of bioprinted constructs and the optimal printable material remain the major research 
focus for printing complex biological structures (70). Detailed and accurate microstructure not only increase similarity to native architecture but can also enable physiological pore size and interconnectivity, which is in turn important when considering that diffusion distances of over $400-500 \mu \mathrm{m}$ limits oxygen and nutrient transport to cells (71). Currently 3-D printing techniques are diverse in properties, some, like stereolithography, provide high resolutions but are limited in appropriate biomaterials and low cell viabilities.

Clinical use of bioprinted structures includes ensuring the safety particularly with regard to growth potentials and practicalities like stem cell banks, upscaling, sterility and storage of tissue-engineered constructs. 3-D bioprinted materials need to comply with good manufacturing practice regulations and need to be approved by regulatory authorities. One of the main difficulties will be to standardize, validate and monitor 3$\mathrm{D}$ bioprinting process from planning and design to manufacturing phase. Due to an utmost individual patient specific and, hence, intrinsically variable process that is extremely troublesome (72). Several bioprinting technologies are promising, but because each tissue currently requires a particular technology, the printing of multicellular tissue constructs is difficult and the mechanical stability of current 'bioinks' are not satisfactory for reconstruction.

\subsection{Experimental studies}

Majority of the research published has focused on the bioprinting of bone, cartilage, and skin. Multiple experimental studies have shown that new bone can be obtained using tissue engineering technology and that several lines of stem cells are available for bone regeneration. The results show that stem cells from deciduous teeth, dental pulp, bone marrow and adipose tissue have the ability to form bone $(16,73,74)$. At present, mesenchymal stem cells are the most commonly used cell types for the bioprinting of bone tissue (Table 1).

Fabricated decellularized trabecular bone scaffold has been to create a mandible condyle. The condyle scaffold was manufactured using CAD - CAM technique. After placing the scaffold into a perfusion bioreactor, the human mesenchymal stem cells (hMSCs) were cultivated on the scaffold. The outcome was assessed using SEM, $\mu C T$ 
and histology. New viable bone was detected and the complex geometry of the neocondyle was obtained. The study suggests that patient-specific bone grafts for craniofacial and orthopedic reconstructions can be provided using tissue engineering (13).

New bone growth in lower jaw using stem cells and polylactic-co-glycolic acid (PLGA) scaffold has been showed to occur in minipig model (12). Critical size bone defects in the mandibular ramus were created and filled with autologous MSCs in PLGA scaffold. The results of this study indicated that autologous MSCs can be manipulated using tissue engineering to form bone for jaw reconstruction.

Other studies confirm that in vivo tissue engineered bone can be used for mandible reconstruction, with mechanical stability comparable to that of a natural bone. A minipig model was to study in vivo bone regeneration in soft tissue. Bovine bone (BioOss ${ }^{\circledR}$ ) blocks and human recombinant bone morphogenetic protein 7 (rhBMP-7) were placed into polylactide mesh scaffold that was implanted into the latissimus dorsi muscle of five animals. The authors were able to show, firstly, that heterotopic bone formation was evident in the muscle and, secondly, that heterotopic bone was histologically similar, and its compression resistance was statistically equal to the natural porcine mandibular bone (75).

Mandiblular condyle has been reconstructed using hydroxyapatite scaffolds manufactured by CAD - CAM technique without cells or growth factors in a sheep model. Hydroxyapatite was shaped with milling machine. Surgical guides and titanium fixation plates were manufactured using laser sintering technique (DMLS). Guides and plates were to bridge the virtual planning with actual surgery. Three sheep were included in this study. The CAD - CAM technology proved to be accurate with a mean difference of $0.25 \mathrm{~mm}$ between virtual plan and actual placement of condyle. After a follow-up of 16 weeks, some bone regeneration was observed deep within the scaffold in addition to the formation of new bone at bone-implant contact. However, in scaffold pores, no evidence of bone was detected (29). 


\subsection{Clinical studies}

Ideally computer modelling should be used in combination with tissue engineering to gain the precise shape and placement of tissue components. The new tools available for surgeons include 3-D CAD, 3D printing, bone substitute materials, growth factors and osteogenic stem cells $(76,77,78)$. The mutual understanding is that bone TE requires osteoconductive matrix, osteoinductive proteins and osteogenic cells (79).

Only scattered clinical facial skeleton reconstruction studies related to both stem cells or bone marrow cells/ aspirate and 3-D CAD - CAM are available $(18,80)$. The results suggest that both human stem cells and bone marrow cells hasten new bone regeneration and enhance early osteogenesis. However, tremendous difference exists between the results of individual clinical studies.

One of the first reports came from Kiel, Germany by Warnke and his coworkers (81). They repaired a mandibular continuity defect using vascularized custom made bone flap with indirect technique by using 3-D computed tomography (CT) and CAD to produce an anatomically precise virtual model for the mandibular defect. On the basis of the virtual model, a titanium scaffold was created. The scaffold was filled with bone mineral blocks, rhBMP-7 and the patient's own bone marrow. The combination was then implanted into the latissimus dorsi muscle. After 7 weeks' maturation, the latissimus dorsi and the solid model combination was transplanted as a free muscle bone flap to reconstruct a mandibular defect. Postoperative CT showed bone remodeling and mineralization. After the follow up of 4 weeks the patient was able to use her mandible and was satisfied with the aesthetic outcome. The authors conclude that heterotopic bone induction by tissue engineering to replace bone in a mandibular defect in human being is possible. Furthermore, this technique allows a lower operative burden compared with conventional techniques by avoiding creation of secondary bone defect. In spite of minor postoperative complications, heterotopic bone induction was evident in the mandible.

A few years later, on 2011, an indirect technique to repair a mandibular defect, caused by removal of an ameloblastoma, with rhBMP-2, $\beta$-TCP and autogenous bone chips added on a collagen sponge together with cortical bone blocks (9). An indirect 3-D PSI manufacturing technique was carried out. The PSI titanium reconstruction plate and 
titanium scaffold filled with the above-mentioned material combination was implanted into defect area and fixed to the mandible. The patient was followed postoperatively for 7 months. At the last visit, the patient was symptomless with stable occlusion. No signs of infection and immature bone were observed. The authors concluded that reconstruction of a larger mandibular defect with the combination of rhBMP-2 and collagen, autogenous bone chips and $\beta$-TCP is possible. The control CT showed good bone formation directed to the center of the defect. The authors also concluded that the reconstruction technique gave a satisfactory result with less invasive surgery and with minimum morbidity. However, studies with larger number of patients are required to indicate the treatment modality as a routine in cases of bone continuity defects.

Matsuo and coworkers used the indirect technique to create a patient-specific solid model (82). After 3-D CAD and surgical simulation, a combination of hydroxyapatite and the PLLA patient-specific mesh tray was produced. Intraoperatively, particulate cancellous bone and marrow was harvested and placed into the hydroxyapatite / PLLA tray with platelet-rich plasma. Two patients were treated and mandible defect repaired. The follow-ups were 28 and 33 months. Dental implants were placed in one of the patients 10 months after initial surgery. In the defect area well-formed bone in hydroxyapatite/PLLA tray was macroscopically observed. The CT evaluation showed excellent bone quality. However, the authors stated that there were several limitations in the trial to draw definite conclusion.

Mesimäki and coworkers published a case report of successful maxillary reconstruction using microvascular flap with heterotopic bone (18) (More in Chapter 7). The same study group performed similar reconstruction to a male patient due to total maxillary defect (Fig $9 \mathrm{a}, \mathrm{b}, \mathrm{c}$ ). The combination of ASCs, $\beta$ TCP granules, rhBMP2 in polylactide scaffold was implanted into anterolateral thigh flap (ALT). Indirect technique was used to shape polylactide scaffold. After maturation of 7 months the microvascular ALT flap with heterotopic bone was raised and placed into defect area. The exact orientation and fixation of the flap with newly formed bone was secured with PSI reconstruction plate. The titanium PSI reconstruction plate was designed and manufactured using direct 3-D CAD - CAM technique. After eventful healing of 5 
months the dental implants were placed and occlusion established with removable prosthesis (not yet published).

This technique was adapted to a mandible reconstruction. Same study group used direct 3-D technique and tissue engineering to repair mandible en bloc defects. 14 patients were included into the study. 3-D CAD - CAM planning was performed and PSIs were designed on virtual model by ProEngineer software. The solid PSI was manufactured using electron beam melting technology. At the surgery PSIs were filled with $\beta$-TCP granules and with autologous cancellous bone chips harvested from iliac crest. Sponge soaked in rhBMP-2 was placed to cover the PSI cages in defects resulted from benign lesion resections to improve the bone formation. All PSIs were covered with collagen membrane and soft tissue microvascular flap. The follow up was between 9-24 months. The overall recovery of the patients was favourable. The facial appearance with respect to symmetry and continuity of the mandible was obtained. Three patients had a major complication. Major dehiscence through soft tissue lead to infection and the PSI needed to be removed. The authors concluded that PSI combined with tissue engineering seems to be a promising solution for treatment of patients demanding large reconstruction of the mandible (83).

Sándor with his coworkers published a case report of mandible reconstruction using the same methodology. No free flap surgery was required. During the follow up, bone regeneration was detected and dental implants were inserted into neomandible. The authors concluded that ASCs in combination with $\mu$ TCP and rhBMP-2 offer a promising construct for treating challenging mandible defects. Bone formation in situ appears to be an attractive alternative for mandibular defect treatment (14).

The largest experience of the use of autologous stem cells with 13 consecutive cases of craniomaxillofacial bone reconstruction is published by Sandor et al technique (15). Out of 13 craniomaxillofacial reconstruction cases, 10 were successful. This study is described in detail in Chapter 7.

The vascularization and nutrition of cells is a key issue of in situ bone regeneration. Recovery of nutrition by prompt assistance of neovascularization is considered to be a key issue of bone regeneration. A central vascular pedicle placed through the 
combination of $\beta$ TCP cylinders seeded with bone marrow was used in order to achieve quicker and better neovascularization. Experimental results were promising (82). In the same paper, a clinical case of craniomaxillary defect that was reconstructed with the combination of autologous iliac crest bone marrow, $\beta$ TCP and rhBMP-2 in titanium scaffold was decribed. More on this study in Chapter 7. However, further research with larger samples and long-term follow up are needed in the future.

\subsection{Conclusions}

There is no doubt that in the future patients will benefit developments both of TE and of 3-D CAD - CAM. The scientists and clinicians are continuously challenging the limits of 3-D technology and TE. There are multiple open questions. One of the most essential issues is the ideal combination of biomaterials, growth factors and stem cells. It is also unclear whether angiogenetic factors are required to develop heterotopic bone to enhance the nutrition for cells.

Although anatomical and functional bone identical to original jaw bone cannot be produced at the present, there is good evidence that the methods will develop and reliable 3-D CAD - CAM and TE produced bone identical to missing bone part is available in the near future. The combination of 3-D and TE may produce novel and profound tools for OMF reconstructive surgery.

Experiences of OMF defect reconstruction using 3-D and "on site" bone tissue engineering have been promising. The main prerequisite of such a reconstruction is that the combination of implanted scaffold, bone substitute material and cells should be completely but loosely covered with soft tissue, preferably thick soft tissue flap. This is to avoid postoperative dehiscence since it will lead to major complications. Salvage of the infected scaffold is almost impossible and leads to removal of the implant. There is no experience on using 3-D together with stem cell technique in cases of an irradiated area. Probably "on site" technique does not function in such cases. The option is to use distant heterotopic bone flap.

The issue of using growth factors to enhance bone growth in 3-D and stem cell reconstruction after malignant tumor resection is not yet solved. 
In conclusion, the 3-D CAD - CAM and stem cell/ bone marrow technique seems to lead to a more accurate reconstruction for jaw defects. It may reduce the donor site complications, since only soft tissue flap is needed instead of bone flap. 3-D CAD CAM may also shorten the operation time, since PSI is immediately available intraoperatively for reconstruction. 


\section{LITERATURE}

1. Kroll SS, Marchi M. (1991) Immediate reconstruction: current status in cancer management. Tex Med 87:67-72.

2. Cohen M, Schoultz RC. (1985) Mandibular reconstruction. Symposium on head and neck surgery. Clin Plast Surg 12:411-422.

3. McQuarrie DG. Oral cancer. In: McQuarrie DG, Adams GL, Shons AR, Brown GA, editors. Head and Neck Cancer. Clinical decisions and management principles. Chicago: Year Book Medical Publishers Inc., 1986

4. Masia J, Kosutic D, Clavero JA et al. (2010) Preoperative computed tomographic angiogram for deep inferior epigastric artery perforator flap breast reconstruction. J Reconstr Microsurg 26:21-28.

5. Lee J, Sung HM, Jang JD et al. (2010) Successful reconstruction of 15-cm segmental defects by bone marrow stem cells and resected autogenous bone graft in central hemangioma. J Oral Maxillofac Surg 68:188-194.

6. Stoor P, Suomalainen A, Lindqvist C et al. (2014) Rapid prototyped patient specific implants for reconstruction of orbital wall defects. J Craniomaxillofac Surg 42(8):1644-1649.

7. Chenard KE, Teven CM, He TC et al. (2012) Bone morphogenetic proteins in craniofacial surgery: current techniques, clinical experiences, and the future of personalized stem cell therapy. J Biomed Biotechnol 2012:1-14.

8. Herford AS, Boyne PJ. (2008) Reconstruction of mandibular continuity defects with bone morphogenetic protein-2 (rhBMP-2). J Oral Maxillofac Surg 66:616624.

9. Zétola A, Ferreira FM, Larson R et al. (2011) Recombinant human bone morphogenetic protein-2 (rhBMP-2) in the treatment of mandibular sequelae after tumor resection. Oral Maxillofac Surg 15:169-174.

10. Hart KL, Bowles D. 2012Reconstruction of alveolar defects using titaniumreinforced porous polyethylene as a containment device for recombinant human bone morphogenetic protein 2. J Oral Maxillofac Surg 70:811-820. 
11. Desai SC, Sclaroff A, Nussenbaum B (2013) Use of recombinant human bone morphogenetic protein 2 for mandible reconstruction. JAMA Facial Plast Surg 15:204-209.

12. Abukawa H, Zhang W, Young CS et al. (2009) Reconstructing mandibular defects using autologous tissue-engineered tooth and bone constructs. J Oral Maxillofac Surg 67:335-347.

13. Grayson WL, Fröhlich M, Yeager K et al. (2010) Engineering anatomically shaped human bone grafts. Proc Natl Acad Sci USA 107:3299-3304.

14. Sándor GK, Tuovinen VJ, Wolff J, et al. (2013) Adipose stem cell tissueengineered construct used to treat large anterior mandibular defect: a case report and review of the clinical application of good manufacturing practicelevel adipose stem cells for bone regeneration. J Oral Maxillofac Surg 71:938-950.

15. Sándor GK, Numminen J, Wolff J, et al. (2014) Adipose Stem Cells Used to Reconstruct 13 Cases With Cranio-Maxillofacial Hard-Tissue Defects. Stem Cells Transl Med. 3(4): 530-540.

16. D’Aquino R, De Rosa A, Lanza V et al. (2009) Human mandible bone defect repair by the grafting of dental pulp stem/progenitor cells and collagen sponge biocomplexes. Eur Cell Mater 18:75-83

17. Fiegel HC, Lange $C$, Kneser $U$ et al. (2006) Fetal and adult liver stem cells for liver regeneration and tissue engineering. J Cell Mol Med 10:577-587.

18. Mesimäki K, Lindroos B, Törnwall J et al. (2009) Novel maxillary reconstruction with ectopic bone formation by GMP adipose stem cells. Int $\mathrm{J}$ Oral Maxillofac Surg 38:201-209.

19. Schön R, Metzger MC, Zizelmann C et al. (2006) Individually preformed titanium mesh implants for a true-to-original repair of orbital fractures. Int $\mathrm{J}$ Oral Maxillofac Surg 35(11):990-995.

20. Mustafa SF, Evans PL, Bocca A et al. (2011) Customized titanium reconstruction of post-traumatic orbital wall defects: a review of 22 cases. Int J Oral Maxillofac Surg 40(12):1357-6132.

21. Stoetzer M, Rana M, von See C et al. (2011) Reconstruction of defects of maxillary sinus wall after removal of a huge odontogenic lesion using prebended 3D titanium-mesh and CAD/CAM technique. Head Face Med $9 ; 7: 21$ 
22. Probst FA, Mast G, Ermer M et al. (2012) Matrix MANDIBLE preformed reconstruction plates--a two-year two-institution experience in 71 patients. $J$ Oral Maxillofac Surg 70(11):657-66

23. Hassfeld S, Mühling J. Computer assisted oral and maxillofacial surgery--a review and an assessment of technology. Int J Oral Maxillofac Surg 2001; $30(1): 2-13$

24. Gellrich NC, Schramm A, Hammer B et al. (2002) Computer-assisted secondary reconstruction of unilateral posttraumatic orbital deformity. Plast Reconstr Surg 110(6):1417-1429

25. Matros E, Albornoz CR, Rensberger M et al. (2014) Computer-Assisted Design and Computer-Assisted Modeling Technique Optimization and Advantages Over Traditional Methods of Osseous Flap Reconstruction. Reconstr Microsurg 30(5):289-296

26. Hou JS, Chen M, Pan CB et al. (2012) Application of CAD/CAM-assisted technique with surgical treatment in reconstruction of the mandible. $J$ Craniomaxillofac Surg 40(8):432-437

27. Wurm G, Tomancok B, Pogady P et al. (2004) Cerebrovascular stereolithographic biomodeling for aneurysm surgery. J Neurosurg. 100(1):139-145

28. Ciocca L, Mazzoni S, Fantini M et al. (2012) CAD/CAM guided secondary mandibular reconstruction of a discontinuity defect after ablative cancer surgery. J Craniomaxillofac Surg 40:511-e515

29. Logan H, Wolfaardt J, Boulanger P et al. (2013) Exploratory benchtop study evaluating the use of surgical design and simulation in fibula free flap mandibular reconstruction. J Otolaryngol Head Neck Surg 24;42:42

30. Ciocca L, Donati D, Fantini M et al. (2013) CAD-CAM-generated hydroxyapatite scaffold to replace the mandibular condyle in sheep: preliminary results. J Biomater Appl 28:207-218

31. Wang L, Chen KC, Shi F et al. (2013) Automated segmentation of CBCT image using spiral CT atlases and convex optimization. Med Image Comput Comput Assist Interv16(Pt 3):251-258

32. Huotilainen $\mathrm{E}$, Paloheimo $\mathrm{M}$, Salmi $\mathrm{M}$ et al. (2014) Imaging requirements for medical applications of additive manufacturing. Acta Radiol 55(1):78-85 
33. Salmi M, Paloheimo KS, Tuomi J et al. (2013) Accuracy of medical models made by additive manufacturing (rapid manufacturing). J Craniomaxillofac Surg 41(7):603-609

34. Schievano S, Sebire NJ, Robertson NJ et al. (2010) Reconstruction of fetal and infant anatomy using rapid prototyping of post-mortem MR images. Insights Imaging 1(4):281-286

35. Izatt MT, Thorpe PLPJ, Thompson RG et al. (2007) The use of physical biomodelling in complex spinal surgery. Eur Spine J 16(9):1507-1518

36. Modabber A, Legros C, Rana M et al. (2012) Evaluation of computer-assisted jaw reconstruction with free vascularized fibular flap compared to conventional surgery: a clinical pilot study. Int J Med Robot 8(2):215-220

37. Han SW, Wang ZY, Hu QG et al. (2014) Combined use of an anterolateral thigh flap and rapid prototype modeling to reconstruct maxillary oncologic resections and midface defects. J Cranio-Maxillofac Surg 25(4):1147-1149

38. Lo LJ, Chen YR, Tseng CS et al. (2004) Computer-aided reconstruction of traumatic fronto-orbital osseous defects: aesthetic considerations. Chang Gung Med J 27(4):283-291

39. Sieira GR, Mari RA, Arranz OC et al. (2015) Surgical planning and microvascular reconstruction of the mandible with a fibular flap using computer-aided design, rapid prototype modelling, and precontoured titanium reconstruction plates: a prospective study. Br J Oral Maxillofac Surg 53(1):49_ 53

40. Zhang YZ, Chen B, Lu S et al. (2011) Preliminary application of computerassisted patient-specific acetabular navigational template for total hip arthroplasty in adult single development dysplasia of the hip. Int J Med Robot 7(4):469-474

41. Hanasono MM, Skoracki RJ. (2013) Computer-assisted design and rapid prototype modeling in microvascular mandible reconstruction. Laryngoscope 123(3):597-604.

42. Foley BD1, Thayer WP, Honeybrook A et al. (2013) Mandibular reconstruction using computer-aided design and computer-aided manufacturing: an analysis of surgical results. J Oral Maxillofac Surg 71(2):111-119 
43. Cha JK, Park JC, Jung UW et al. (2011) Case series of maxillary sinus augmentation with biphasic calcium phosphate: a clinical and radiographic study. J Periodontal Implant Sci 41(2):98-104

44. Lindgren C, Mordenfeld A, Hallman M et al. (2012) A prospective 1-year clinical and radiographic study of implants placed after maxillary sinus floor augmentation with synthetic biphasic calcium phosphate or deproteinized bovine bone. Clin Implant Dent Relat Res 14(1):41-50

45. Pandit N, Gupta R, Gupta S. (2010) A comparative evaluation of biphasic calcium phosphate material and bioglass in the treatment of periodontal osseous defects: a clinical and radiological study. J Contemp Dent Pract $1 ; 11(2): 25-32$

46. Piitulainen JM, Kauko T, Aitasalo KM et al. (2015) Outcomes of cranioplasty with synthetic materials and autologous bone grafts. World Neurosurg 83(5):708-714.

47. Ioannou AL, Kotsakis GA, Kumar T et al. (2015) Evaluation of the bone regeneration potential of bioactive glass in implant site development surgeries: a systematic review of the literature. Clin Oral Investig19(2):181-91

48. Mironov V. (2005) The Second International Workshop on bioprinting, biopatterning and bioassembly. Expert Opin Biol Ther 5(8):1111-1115

49. Vacanti CA. (2006) The history of tissue engineering. J Cell Mol Med 10:569576

50. Ingber DE. (2005) Mechanical control of tissue growth: function follows form. PNAS 102(33):11571-11572

51. Dowler C. (1989) Automatic model building cuts design time, costs. Plast Eng $45-43$

52. Fisher JP, Dean D, Mikos AG et al. (2002) Photocrosslinking characteristics and mechanical properties of diethyl fumarate/poly (propylene fumarate) biomaterials. Biomaterials 23:4333-4343

53. Melchels FP, Feijen J, Grijpma DW et al. (2009) A poly (D, L-lactide) resin for the preparation of tissue engineering scaffolds by stereolithography. Biomaterials 30:3801-3809

54. Chan V, Zorlutuna P, Jeong JH et al. (2010) Three dimensional photopatterning of hydrogels using stereolithography for long-term cell encapsulation. Lab Chip 10:206-270 
55. Jakab K, Norotte C, Damon B et al. (2008) Tissue engineering by selfassembly of cells printed into topologically defined structures. Tissue Eng A $14: 413-421$

56. Landers R, Hübner U, Schmelzeisen R et al. (2002) Rapid prototyping of scaffolds derived from thermoreversible hydrogels and tailored for applications in tissue engineering. Biomaterials 23:4437-4447

57. Seol YJ, Kang HW, Lee SJ et al. (2014) Bioprinting technology and its applications. Eur J Cardiothorac Surg 46(3):342-348

58. Ringeisen BR, Kim H, Barron JA et al. (2004) Laser printing of pluripotent embryonal carcinoma cells. Tissue Eng 10: 483-491

59. Hopp B, Smausz T, Kresz N et al. (2005) Survival and proliferative ability of various living cell types after laser-induced forward transfer. Tissue Eng 11:1817-1823

60. Gruene M, Pflaum M, Hess C et al. (2011) Laser printing of threedimensional multicellular arrays for studies of cellecell and cell environment interactions. Tissue Eng C Methods 17: 973-982

61. Boland T, Xu T, Damon B et al. (2006) Application of inkjet printing to tissue engineering. Biotechnol J 1(9):910-917

62. Xu T, Gregory CA, Molnar P et al. (2006) Viability and electrophysiology of neural cell structures generated by the inkjet printing method. Biomaterials 27:3580-3588

63. Cui X, Boland T. Human microvasculature fabrication using thermal inkjet printing technology. Biomaterials 2009; 30:6221-6227

64. Parzel CA, Pepper ME, Burg T et al. (2009) EDTA enhances high-throughput two-dimensional bioprinting by inhibiting salt scaling and cell aggregation at the nozzle surface. J Tissue Eng Regen Med 3(4):260-268

65. Mironov V, Kasyanov V, Markwald RR. (2008) Nanotechnology in vascular tissue engineering: from nanoscaffolding towards rapid vessel biofabrication. Trends Biotechnol 26(6): 338-344

66. Buyukhatipoglu K, Chang R, Sun W et al. (2010) Bioprinted nanoparticles for tissue engineering applications. Tissue Eng C Methods 16(4):631-642

67. Konig G, McAllister TN, Dusserre N et al. (2009) Mechanical properties of completely autologous human tissue engineered blood vessels compared to human saphenous vein and mammary artery. Biomaterials 30(8):1542-1550 
68. Mandrycky C, Wang Z, Kim K et al. (2016) 3D bioprinting for engineering complex tissues. Biotechnol Adv 34(4):422-434

69. Naito H, Dohi Y, Zimmermann WH et al. (2011) The effect of mesenchymal stem cell osteoblastic differentiation on the mechanical properties of engineered bone-like tissue. Tissue Eng A 17:2321-2329

70. He Y, Yang F, Zhao H et al. (2016) Research of the printability of hydrogels in 3D bioprinting. Sci Rep 20(6): 2997-2997

71. Chia HN, Wu BM. Recent advances in 3D printing of biomaterials. J Biol Eng 2015 Mar 1; 94

72. Lee MH, Arcidiacono JA, Bilek AM et al. (2010) Considerations for tissueengineered and regenerative medicine product development prior to clinical trials in the United States. Tissue Eng B Rev 16(1):41-54

73. Warnke PH, Springer IN, Acil Y et al. (2006) The mechanical integrity of in vivo engineered heterotopic bone. Biomaterials. 27(7):1081-1087

74. Yamada Y, Ito K, Nakamura S et al. (2011) Promising cell-based therapy for bone regeneration using stem cells from deciduous teeth, dental pulp, and bone marrow. Cell Transplant 20:1003-1013

75. Xu H, Han D, Dong JS et al. (2010) Rapid prototyped PGA/PLA scaffolds in the reconstruction of mandibular condyle bone defects. Int J Med Robot 6:6672.

76. Warnke PH, Springer IN, Acil Y et al. (2006) The mechanical integrity of in vivo engineered heterotopic bone. Biomaterials 2006 ;27(7):1081-1087

77. Bibb R, Thompson D, Winder J et al. (2011) Computed tomography characterisation of additive manufacturing materials. Med Eng Phys 33(5):590-596

78. Hassfeld S, Mühling J, Zöller J. (1995) Intraoperative navigation in oral and maxillofacial surgery. Int J Oral Maxillofac Surg 24:111-119

79. Niemelä SM, Miettinen S, Konttinen Y et al. (2007) Fat tissue: views on reconstruction and exploitation. J Craniofac Surg 18:325-235

80. Huang JI, Zuk PA, Jones NF et al. (2004) Chondrogenic potential of multipotential cells from human adipose tissue. Plast Reconstr Surg 113:585594

81. Li J, Hsu Y, Luo E et al. (2011) Computer-aided design and manufacturing and rapid prototyped nanoscale hydroxyapatite/polyamide (n-HA/PA) 
construction for condylar defect caused by mandibular angle ostectomy. Aesthet Plast Surg 35(4):636-640

82. Warnke PH, Springer IN, Wiltfang J et al. (2004) Growth and transplantation of a custom vascularised bone graft in a man. Lancet. 364(9436):766-770

83. Matsuo A, Chiba H, Takahashi $\mathrm{H}$ et al. (2010) Clinical application of a custommade bioresorbable raw particulate hydroxyapatite/poly-L-lactide mesh tray for mandibular reconstruction. Odontology 98(1):85-88

84. Stoor P, Suomalainen A, Mesimäki K et al. (2017) Rapid prototyped patient specific guiding implants in critical mandibular reconstruction. $J$ Craniomaxillofac Surg 45(1):63-70

85. Kokemueller H, Spalthoff $S$, Nolff $M$ et al. (2010) Prefabrication of vascularized bioartificial bone grafts in vivo for segmental mandibular reconstruction: experimental pilot study in sheep and first clinical application. Int J Oral Maxillofac Surg 39(4):379-387 
Fig. 9.1 a) Virtual CAD model after planning the resection surgery with individual cutting guide and onlay implant to support soft tissue of the face, b) Titanium PSI onlay manufactured using laser sintering technique based on virtual design, c) Intraoperative view after resection and PSI onlay in place

Fig 9.2. The 3-D CAD - CAM flow includes several critical stages from 3-D imaging to surgery and to final reconstruction. The figure shows the flow of dental implant surgery. It starts from CBCT imaging, continues after format conversion to digital design and planning to manufacturing of drilling guides and finally guides are used to support precise drilling and placing the implants

Fig. 9.3 Artefacts in virtual CAD model based on incorrect slice thickness, distorsion and move of the patient during imaging

Fig 9.4 a) Virtual implant designed on fractured orbit wall, b) Virtual PSI ready for printing, stl file, c) Solid PSI manufactured using laser technique (courtesy of Planmeca)

Fig 9.5 a) Virtual CAD model to showing tumour andn planned resection margind, b) CAD modelwith resection performed and virtual PSI in place. c) cutting guides designed, d) PSI CAD reconstruction plate ready to be manufactured (courtesy of Planmeca)

Fig $9.6 \mathrm{a}$ and b) Fully automatic condyle repositioning using collision algorithms, c) automated digital orbit volume calculation, d) FEM based analysis of forces influencing condyle neck fracture, e) analysis of position of small bones of foot and ankle (courtesy of Disior)

Fig. 9.7 a) Virtual PSI jig to guide onlay implant placement, note drilling holes, b) Intraoerative view of drilling guiding holes for the onlay implant, c) patient before the surgery, d) after surgery

Fig. 9.8 The use of 3D printing technology with materials that incorporate viable living cells, e.g. to produce tissue for reconstructive surgery (courtesy of AO Foundation)

Fig. 9.9 a) Preoperative CT 3-D data used to outline patient maxilla after resection operation, fusion of re- and postoperative CT data, b) virtual scaffold designed based o fusion data, c) CAD 3-D image after reconstruction, data obtained from CT data 
Kontio's figures

Fig $9.1 a, b, c$
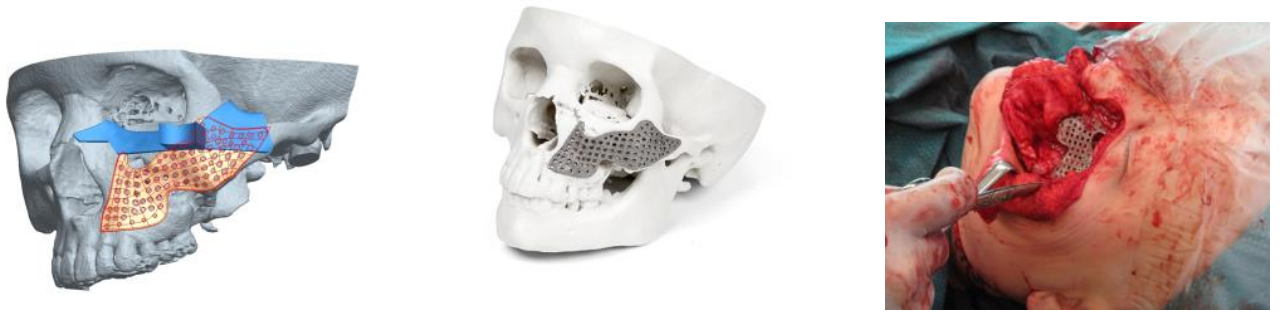

Fig 9.2

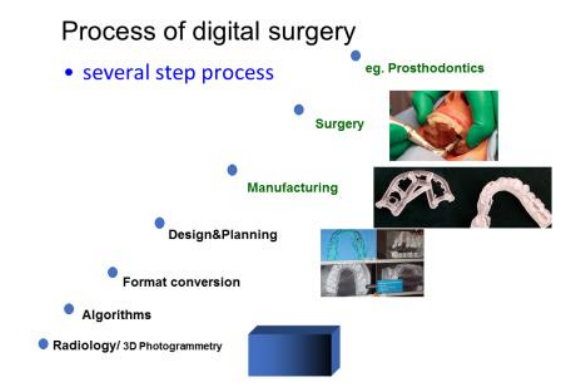

Fig 9.3

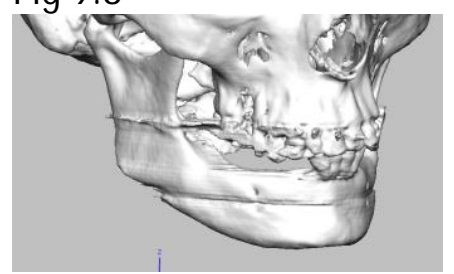

Fig $9.4 a, b, c$
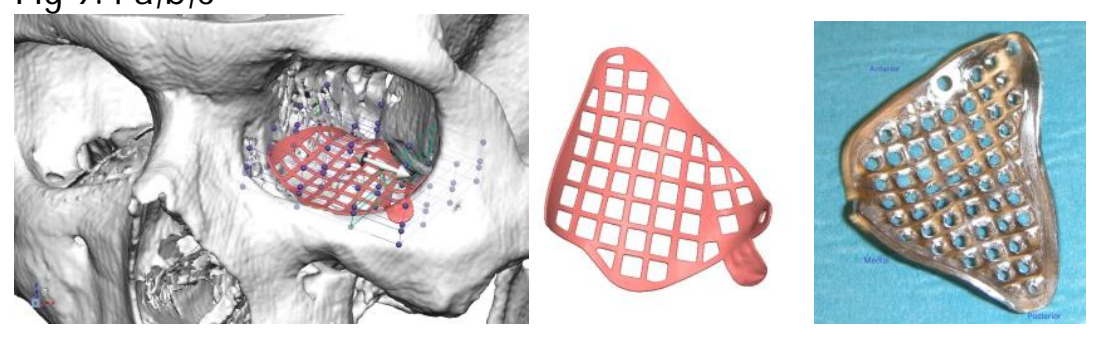

Fig $9.5 \mathrm{a}, \mathrm{b}, \mathrm{c}, \mathrm{d}$

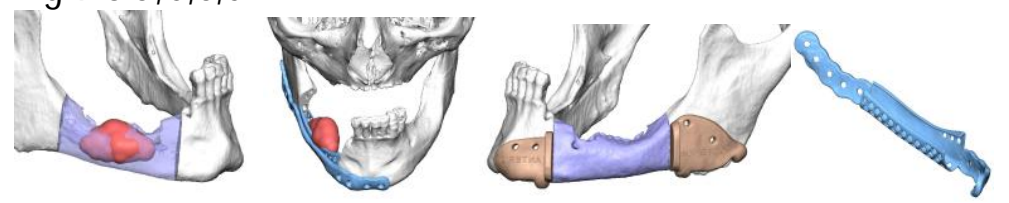

Fig 9.6a,b,c,d,e

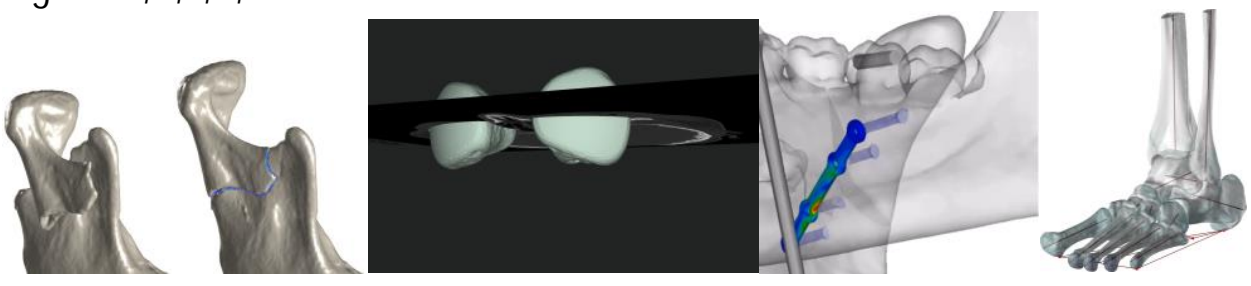


Fig 9.7 a,b,c,d
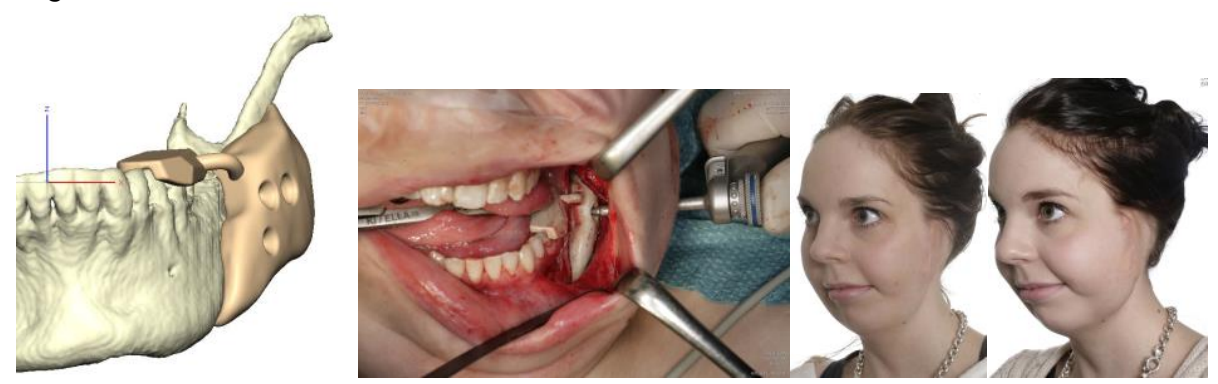

Fig 9.8
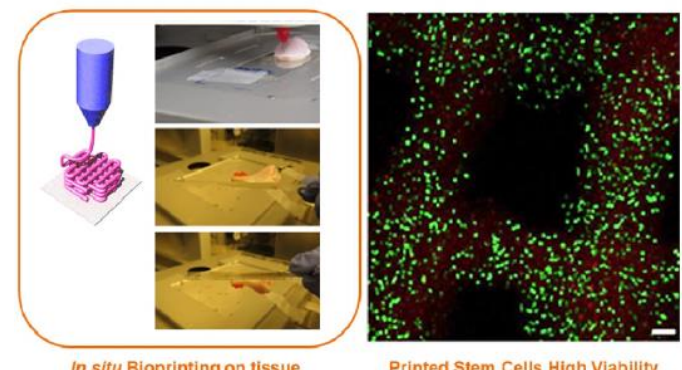

Printed Stem Cells High Viability

Fig $9.9 a, b, c$
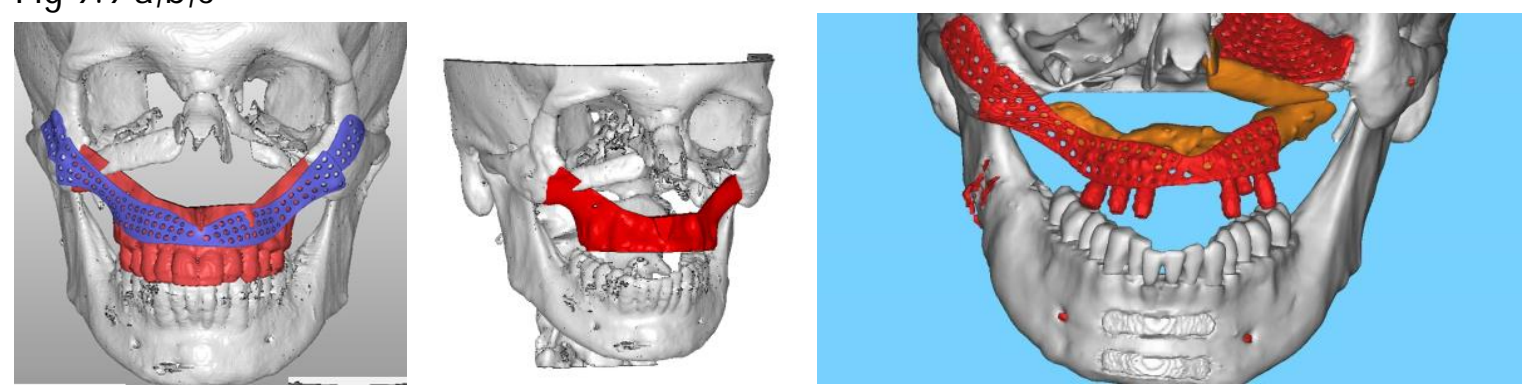


\section{Table 9.1}

Available bioprinting techniques and their main properties

\begin{tabular}{|c|c|c|c|}
\hline $\begin{array}{l}\text { Stereolithograph } \\
\text { E.g. photosolidification }\end{array}$ & $\begin{array}{l}\text { Polymerisation of } \\
\text { photocurable resin } \\
\text { layer by layer }\end{array}$ & $\begin{array}{l}\text { Extremely high } \\
\text { resolution enables to } \\
\text { create complex } \\
\text { shapes and } \\
\text { microstructure }\end{array}$ & $\begin{array}{l}\text { Only few proper } \\
\text { biomaterials, } \\
\text { Poor mechanical } \\
\text { properties }\end{array}$ \\
\hline $\begin{array}{l}\text { Laser assisted } \\
\text { E.g. Laser-guided direct } \\
\text { writing }\end{array}$ & $\begin{array}{l}\text { Deposition of cells } \\
\text { either in a laser beam } \\
\text { or using pulsed laser } \\
\text { for transfer }\end{array}$ & $\begin{array}{l}\text { High resolution } \\
\text { Compatible with wide } \\
\text { range of biomaterial } \\
\text { viscosities }\end{array}$ & Lower cell viability \\
\hline $\begin{array}{l}\text { Extrusion based } \\
\text { E.g. Fused deposition } \\
\text { modelling }\end{array}$ & $\begin{array}{l}\text { Viscous liquid or } \\
\text { molten material } \\
\text { extruded through } \\
\text { nozzle as a } \\
\text { continuous strand of } \\
\text { individual dots }\end{array}$ & $\begin{array}{l}\text { Deposit clusters of } \\
\text { cells } \\
\text { Scaffolds for soft } \\
\text { tissue engineering }\end{array}$ & $\begin{array}{l}\text { Material viscosity and } \\
\text { potential for } \\
\text { leaks can affect } \\
\text { resolution } \\
\text { Limited mechanical } \\
\text { stiffness }\end{array}$ \\
\hline $\begin{array}{l}\text { Inkjet based } \\
\text { E.g. thermal 3-D inkjet } \\
\text { bioprinting }\end{array}$ & $\begin{array}{l}\text { Photopolymer-based } \\
\text { bio-ink is } \\
\text { jetted by an inkjet and } \\
\text { cured } \\
\text { with UV light }\end{array}$ & $\begin{array}{l}\text { High resolution } \\
\text { Complex scaffolds } \\
\text { with microstructure } \\
\text { control }\end{array}$ & $\begin{array}{l}\text { Risk for cell death at } \\
\text { higher temperatures } \\
\text { and pressures } \\
\text { Limited available } \\
\text { pore sizes }\end{array}$ \\
\hline $\begin{array}{l}\text { Nanoscale } \\
\text { E.g. Dip pen } \\
\text { nanolithography }\end{array}$ & $\begin{array}{l}\text { Electron beam } \\
\text { polymerisation or } \\
\text { atomic force } \\
\text { microscope probes }\end{array}$ & $\begin{array}{l}\text { Allows scaffold } \\
\text { surface modification } \\
\text { on the nanoscale for } \\
\text { additional } \\
\text { functionality } \\
\text { Nanoscale printing } \\
\text { can manipulate and } \\
\text { track bioactive factors } \\
\text { and cells }\end{array}$ & $\begin{array}{l}\text { Nanoparticles can } \\
\text { lose viability post } \\
\text { printing } \\
\text { Currently little is } \\
\text { known on cell } \\
\text { behaviour }\end{array}$ \\
\hline
\end{tabular}

